\title{
Pesa, logo existe: por uma antropologia que corra (perigo)
}

\author{
AMANDA HORTA $\mathbb{D}$ \\ Universidade Federal de Ciências da Saúde de Porto Alegre, Porto Alegre, Rio \\ Grande do Sul, Brasil \\ amandahorta@gmail.com \\ RENATO JACQUES \\ Universidade de São Paulo, São Paulo, São Paulo, Brasil \\ jacquesdebrito@yahoo.com.br
}

DOI 10.11606/issn.2316-9133.v29i2pe171329

\begin{abstract}
resumo Este artigo se dá na interseção entre dois trabalhos de campo, um entre indígenas do Território Indígena do Xingu que habitam a cidade de Canarana, Mato Grosso, outro com grupos de danças contemporâneas na cidade de São Paulo. Nossa intenção é ressaltar os importantes efeitos de se levar a sério a possibilidade de que outros mundos levem a outros modos de conhecimento, estabelecendo, desde a perspectiva do corpo e de seus poderes modulatórios, uma crítica a abordagens estritamente intelectuais de saberes que chamam à experiência direta. $\mathrm{O}$ que sugerimos aqui é uma radicalização da proposta de se levar a sério a verdade de nossas interlocutoras e interlocutores de pesquisa, não apenas escutando suas verdades como verdades para elas, mas escutando-as como verdades que definem, ela mesmas, os limites de sua extensão.
\end{abstract}

palavras-chave Teoria antropológica. Antropologia do corpo. Etnologia ameríndia. Antropologia da dança. Descolonização epistêmica

\section{As heavy, as real: towards a running anthropology (in danger)}

abstract This article takes place at the intersection of two field works, one among the indigenous people of the Xingu Indigenous Territory who live in the city of Canarana, the other with contemporary dance groups in the municipality of São Paulo. Our goal is to highlight the effects of taking seriously the possibility that other worlds may lead to other modes of knowledge. Considering the perspective of the body and its modulatory powers, we establish a critique of strictly intellectual approaches to knowledges that demand direct experience. What we suggest here is a radicalization of the classic proposition of taking 
seriously the truth of our research interlocutors, by not only listening to their truths as truths for them but listening to them as truths that define the limits of their extension.

keywords Anthropological theory. Anthropology of the body. Amerindian Ethnology. Anthropology of dance. Epistemic decolonization

\section{Pesa, luego existe: hacia una antropología que corra (peligro)}

resumen Este artículo se desarrolla en la intersección de dos trabajos de campo, uno entre indígenas del Territorio Indígena Xingu que viven en la ciudad de Canarana, otro con grupos de danza contemporánea en la ciudad de São Paulo. Nuestra intención es resaltar los efectos importantes de tomar en serio la posibilidad de que otros mundos puedan conducir a otros modos de conocimiento, estableciendo, desde la perspectiva del cuerpo y sus poderes moduladores, una crítica de enfoques estrictamente intelectuales del conocimiento que llaman a la experiencia directa. Lo que sugerimos aquí es una radicalización de la propuesta de tomar en serio la verdad de nuestras interlocutoras e interlocutores de investigación, no solo escuchando sus verdades como verdades para ellos, sino escuchándolas como verdades que definen, ellas mismas, los límites de su extensión.

resumen Teoría Antropológica. Antropología del cuerpo. Etnología. Antropología de la danza. Descolonización epistemológica.

\section{Introdução}

Este artigo é fruto de algumas conexões parciais feitas entre os trabalhos de Renato Jacques, com grupos de danças contemporâneas na cidade de São Paulo (SP), e de Amanda Horta, entre pessoas indígenas do Território Indígena do Xingu (TIX) que ocupam o centro urbano da cidade de Canarana (MT). Apesar da nítida diferença entre tais campos, nossas pesquisas apontam a importância de se levar a sério a possibilidade de que outros mundos levem a outros modos de conhecimento, enfatizando as torções que a disposição em experimentar esses outros modos confere à produção acadêmica que deles resulta. Nosso ponto de partida é a constatação de que, ainda que certas interlocutoras e interlocutores de pesquisa digam, a todo instante, que o conhecimento é (ou se dá através da) transformação corporal, antropólogas e antropólogos tendem a privilegiar abordagens intelectualistas desses saberes que chamam à experiência.

O que estamos sugerindo é a radicalização da máxima que propõe levar a sério a verdade de nossas interlocutoras e interlocutores de pesquisa, algo que, segundo Márcio Goldman (2016), seria uma das grandes tarefas da antropologia. A proposta não é apenas escutar suas verdades como verdades para elas, numa postura relativista e transcendente, amaldiçoada pela tolerância, mas escutá-las como verdades que definem, elas mesmas, em regime de imanência, os limites de sua extensão. Nossa sugestão é de que, se apenas as palavras são levadas a sério, e apenas do ponto de vista intelectual, então nossas interlocutoras e interlocutores podem não estar sendo levadas a sério de todo. Nossa aposta 
é que a perspectiva intelectualista, que molda os hábitos ocidentais de pesquisa, coloniza as demais perspectivas e também os mundos que essas perspectivas estão aptas a instaurar. Nossa percepção é de que a postura intelectual se mostra insuficiente no que se refere à apreensão de existências dançantes, saltitantes, andarilhas, moventes, errantes, metamórficas, e tal limitação nos parece começar pelo corpo. Em um momento histórico tão crítico para as humanidades, a antropologia tem um papel fulcral na transformação de certas perspectivas existenciais, em especial aquelas cujo funcionamento exige o extermínio de outras tantas perspectivas. Ao afirmar a possibilidade de dimensões epistemológicas e ontológicas que não se assentam sobre o intelecto, argumentamos que apenas aprendendo outras formas de aprender é que poderemos imaginar outros futuros possíveis.

\section{E se nem todos param para pensar?}

Nossa âncora se firma no último giro da filosofia ocidental, a tão falada virada ontológica que, segundo consta, vem se sobrepor à virada linguística que "converteu todas as questões ontológicas em questões epistemológicas” (VIVEIROS DE CASTRO 2012). Com a virada linguística, assentam-se as bases do multiculturalismo, toda e qualquer diferença cultural sendo, então, tomada no sentido de modos distintos de pensar uma mesma condição (ou lógica) humana - com várias línguas a traduzir uma mesma natureza compartilhada. Tal diferença seria o objeto antropológico por excelência. Hasteia-se a bandeira do relativismo cultural que propõe a existência de um único mundo objetivo diferentemente apreendido (subjetivamente) por cada cultura. A virada ontológica, por sua vez, recusa a interpretação linguística e devolve ao mundo (ou aos mundos) a diferença que havia sido posta no olhar: trata-se de reconhecer a existência de mundos que não dependem da prerrogativa de serem interpretados, ou seja, mediados pelos significados (linguísticos) atribuídos por alguém ou por uma cultura. Perde-se o mundo como nomos global e totalizante, ganha-se uma miríade de mundos possíveis, existentes e porvir.

Com a ontologia virada, o mundo ocidental é, portanto, apenas um entre uma infinidade de outros mundos. Um mundo habitado por aqueles que se entendem como modernos, industriais, urbanos, gente de raízes escritas, cuja corporalidade assentada sobre cadeiras privilegia um certo modo de ver. Nesse mundo, boa parte das práticas de apreensão, produção e transmissão de conhecimento, formais e informais, se dá sob tal postura corporal, postura que literalmente seda o corpo e estabiliza a percepção, especialmente o olhar.

Para objetificar o olhar e o corpo que olha, o projeto moderno os tornou estáticos. Em sua forma ideal, o olhar ocidental se dá parado, assim como o pensamento. Trata-se de uma corporalidade que não apenas reivindica o olhar como sentido privilegiado, mas que o idealiza e o realiza em modo estático. Lê-se com o corpo parado, assiste-se com o corpo parado, escreve-se com o corpo, igualmente, parado. Sob a égide de tal projeto, é preciso "parar para pensar". Com isso, o gesto de sentar ganha a relevância de toda uma cultura.

Esse olhar, "cultural", com base estática é, nesse mundo, conceitualizado e experimentado enquanto mediador do conhecimento. Mediação que não é neutra, e que 
subjaz a constante presunção da distância. Conhece, sabe, quem parou e tomou distância para ver. Uma distância que se vive como uma separação ontológica entre quem conhece e o que é conhecido. A mediação dos olhos marcada por essa separação: os olhos do "sujeito" a mirar o "objeto", os olhos do "eu" a olhar o "mundo", do "eu" a olhar o "outro". Eis o sentido, nesse mundo, da separação entre "dentro" e "fora”. Nesse mundo, quem olha não está lá. O voyeur pode nos servir de exemplo, mas também as câmeras de vigilância. Porém, a concepção ocidental do olhar não é intrínseca ao olhar em si. Há que se perguntar até mesmo se há um "olhar em si", uma vez que as diferentes experiências de olhar, que se traduzem em etnografias mundo afora, não levam necessariamente à separação ontológica entre dois modos de existência ou mesmo à automática objetificação do que é visto, do que é exterior.

Não é preciso ir longe. Há, mesmo em contextos urbanos, uma ampla gama de práticas corporais (coletivas, artísticas, terapêuticas) que instauram, e assim demonstram, espaços de criação e apreensão de mundos que fazem desabituar o olhar enquanto órgão da separação entre o "interior" e o "exterior". Tratam-se de práticas em cujos territórios os limites entre o corpo e o mundo se desdobram, por exemplo, recolocando o olhar em aliança com o movimento, o que ressalta a plasticidade do olhar, ou seja, a capacidade que diferentes modos de olhar têm de alterar, diferentemente, a dimensão das coisas olhadas. Quando somos, por exemplo, instigados a perceber o espaço da visão enquanto algo que "tanto nos cerca quanto passa através de nós" (INGOLD 2008), quando Merleau-Ponty (1968) sugere reviver o olhar enquanto experiência de luz, de abertura para o mundo, quando a visão é o sentido da imersão na luz que a tudo embebe, algo então se altera de modo, digamos, global: a visão já não é das coisas, mas se dá em meio a elas. O olhar que se dá em meio a outras coisas é um olhar não-linguístico.

Não são os olhos que objetificam o mundo, afirma Ingold, mas o projeto moderno que cooptou os olhos com fins à objetificação do mundo. Não à toa, Ingold traz o velho, e ainda bom exemplo, do olhar que percorre uma prateleira de supermercado, do olhar que se habituou à percepção do mundo enquanto objeto, ou, mais especificamente, do mundo enquanto conjunto de commodities. "É através de sua cooptação a serviço de um projeto peculiarmente moderno de objetificação que a visão tem sido reduzida à faculdade de reflexão pura e desinteressada, cujo papel é meramente o de entregar 'coisas' a uma consciência transcendente" (2008: p.11).

A despeito dos rumos desse projeto moderno, o movimento, o deslocamento, o caminhar estão ligados aos primórdios da filosofia ocidental. Lembremos a Escola Peripatética, daqueles que praticavam o pensamento perambulatório, o conhecimento em trânsito. Peripatético significa ambulante ou itinerante. Peripatéticos eram os que, capitaneados por Aristóteles (384-322 a.C), filosofavam ao passo que passeavam, em geral descalços. Vale lembrar que em Fedro, texto considerado porta de entrada para os principais temas da filosofia de Platão (428-347 a.C), este nos coloca diante de uma série de discursos proferidos durante uma caminhada fora dos muros de Atenas. 
Conhecer em íntima relação com o caminhar, conhecimento e errância. Mas a estratégia de um projeto civilizacional que requer a objetificação do mundo foi assentar o errante-conhecedor. $\mathrm{O}$ aspecto errante do pensamento se torna assim persona non grata a tal projeto. Basta pensar numa sala de aula convencional. O distanciamento entre o conhecimento de corpo inerte e as práticas de conhecer em movimento reforça que conhecer sentado é, em todos os sentidos, conhecer sem errar, conhecer sem correr perigos. Porém, muitas evidências indicam que o movimento pode se constituir enquanto estratégia fundamental ao conhecimento. Há até mesmo neurocientistas a afirmar, por meio de seus experimentos, que a razão última do cérebro é o movimento (WOLPERT 2011). De todo modo, o caráter errante parece ser de fato inerente ao conhecimento. Bruno Latour (2000), por exemplo, interessado em pesquisar as práticas cotidianas da pesquisa científica, mostrou como a Ciência com c maiúsculo (LATOUR 2004; STENGERS 2017), fria, poderosa, pronta e acabada, oculta em seu discurso os seus processos, suas hipóteses e seus experimentos malsucedidos, os tantos ajustes metodológicos necessários à pesquisa, suas idas e vindas, sua errabilidade inerente e constante. Mas, afinal, de onde vem esse ideal de conhecimento, que se adquire sem movimento, sem errar, sem riscos?

Em O pensamento sentado (2012), Norval Baitello Junior nos apresenta o que seria, para Vilém Flusser, a história (mítica) desse mundo do conhecimento não errante. Não se trata, pois, da história da humanidade, mas da história de um certo tipo de mundo.

O ser humano, em sua evolução, sobreviveu a três grandes catástrofes, diz Flusser: a primeira delas, a hominização, com a descida das copas das árvores, a necessidade do caminhar bípede e ereto. Da primeira catástrofe surge um ser nômade que na atividade de "fahren" ("deslocar-se" em alemão) desenvolve o "erfahren" ("tomar conhecimento, reunir experiências"). A segunda catástrofe, denominada "civilização", modifica sua natureza de forma radical, inserindo-o fixamente na vida em aldeias, em torno das quais são domesticados e cultivados vegetais e animais. Surge aí o assentado (cujo verbo em alemão é "sitzen", "estar sentado"), o possuidor e acumulador de bens (do verbo "besitzen", "possuir"). Flusser argumenta com a língua alemã, mas pode-se confirmar o mesmo na língua latina (e suas derivadas), na qual os verbos são igualmente irmãos: "sedere" e "possedere", sentar e possuir (em espanhol, o verbo "poseer" mostra mais claramente a proximidade com o "possedere"). Durante esse breve período sedentário de pouco mais de 10 mil anos, no aconchego e na proteção das habitações, surgem a escrita e os sistemas lógicos dela advindos, sistemas numéricos e de cálculos, que permitiram o desenvolvimento da ciência e da técnica (BAITELLO JUNIOR 2012: p.27) 
A terceira catástrofe, vale a pena complementar, seria o "nomadismo sentado", assim o define Flusser, a viagem ocular de corpos sedados frente a máquinas de imagens. Eis o lugar onde encontramos agora o ocidental-sentado, o não errante, ou ainda, como formulou LéviStrauss (1989), o "pensamento domesticado", aquele que, numa leitura pós-estrutural, serviria a pensar um mundo que se apresenta domesticável. Porém, se à antropologia, contra sua cultura de origem, cabe abrir as sendas para outros modos de conhecer, é preciso questionar a própria domesticabilidade dos mundos, sobretudo daqueles que resistem, não sem bravura e a duras penas, à colonização de seus territórios existenciais.

\section{Corpos bons para...}

Tomemos, por exemplo, os mundos ameríndios. No final dos anos 1970, Anthony Seeger, Roberto Da Matta e Eduardo Viveiros de Castro afirmavam já a necessidade de se tomar "o discurso indígena sobre a corporalidade e a pessoa como informador da práxis social concreta e única via não-etnocêntrica de inteligibilidade desta práxis” (1979). Nesse sentido, como uma infinidade de autoras e autores têm demonstrado - dentre elas, inclusive, autoras e autores indígenas -, o conhecimento ameríndio está, ele mesmo, condicionado às transformações corporais (e vice-versa) (CORREA XAKRIABÁ 2018; VILAÇA 2005; TAYLOR 1996). A experiência do puerpério nas aldeias do complexo multiétnico do Alto $\mathrm{Xingu}^{1}$ é um exemplo célebre. Durante a gestação, mas, sobretudo, após o nascimento do bebê, os pais se dedicam a um longo processo de cuidados que condicionam a humanidade da criança. Resguardam-se nas primeiras semanas, modelam o corpo da criança com massagens vigorosas, observam restrições e prescrições alimentares, sexuais e comportamentais. Se o corpo do recém-nascido responde às ações dos parentes, ele se humaniza. $\mathrm{O}$ ato de criar um bebê tem menos a ver com a transmissão de conhecimentos para a criança, do que com a transformação de seu corpo. O que se passa aqui não é, definitivamente, um suposto desenvolvimento intelectual da criança, mas a transformação de seu corpo inicialmente disforme.

Algo similar se passa com as pessoas alto-xinguanas lutadoras de Huka Huka, que se preparam para as lutas se arranhando, fazendo restrições sexuais e alimentares, e tomando eméticos antes de lutar. A eficácia desses procedimentos se manifesta no corpo da pessoa, que fica forte, firme, e no resultado de suas lutas. Os conhecimentos ameríndios existem, sobretudo, encorporados ${ }^{2}$ na vida saudável da criança e na vitória de quem luta. Conhecer,

\footnotetext{
${ }^{1}$ Xingu se caracteriza pela existência de um sistema regional de relações indígenas, um conjunto de povos falantes de línguas aruak (Wauja, Mehinaku e Yawalapiti), karib (Kuikuro, Kalapalo, Matipu, Nahukwá), tupi (Kamayurá e Aweti), além dos Trumai, falantes de uma língua isolada. Esses povos partilham uma definição recíproca de humanidade, uma estética ritual, uma terminologia de parentesco e um corpus mítico relativamente homogêneo.

2 Seguimos aqui a proposição de Eduardo Viveiros de Castro presente em nota no artigo intitulado Perspectivismo e Multinaturalismo na América Indígena (2002: p.374): "traduzo o verbo inglês to embody (...) pelo neologismo 'encorporar', visto que nem 'encarnar' nem 'incorporar' são realmente adequadas”.
} 
saber, é sempre experimentar, moldar: o corpo é o idioma focal das sociedades ameríndias (SEEGER; DAMATTA; VIVEIROS DE CASTRO 1979).

Tudo isso implica que aprender, nesses mundos, não é um dispositivo meramente intelectual, mas que requer, sobretudo, uma modulação física. Nas palavras de Tânia Stolze Lima no mundo ameríndio

(...) o verdadeiro conhecimento é condicionado, não pela retirada do sujeito, mas por sua apropriação de uma posição dentre as muitas ali existentes, pois o conhecimento exato e pleno da realidade que se pode assim observar e viver supõe e mesmo obriga sua completa imersão. É, pois, um mundo em que não se poderia opor nem dissociar o pensado e o vivido sem no mesmo lance perder o mais fundamental. (LIMA 2002: p.17),

A radicalidade de tal formulação não está apenas naquilo que ela descreve, isto é, no que ela diz sobre os ameríndios, mas, sobretudo, naquilo que ela propõe: a possibilidade de um conhecimento que recusa a objetificação, em nome da assunção de uma perspectiva, isto é, de sua existência encorporada.

Do ponto de vista intelectual, essa proposição sem dúvida desloca e assim acresce ao conhecimento antropológico, levando à fundação de novas, ou ao questionamento de velhas matrizes conceituais. Contudo, a práxis acadêmica da antropologia, não só nos meandros da etnologia ameríndia, mas nos seus mais diversos campos, segue ainda firmada majoritariamente na corporalidade linguística moderna, na cultura enquanto subjetividade, no olhar parado e distanciado. O conhecimento antropológico continua atrelado à produção de teses que são escritas e empilhadas em arquivos físicos ou digitais. Mas seriam os corpos daquelas e daqueles com quem pesquisamos, de fato, apenas bons para pensar?

Muitas etnógrafas e etnógrafos em contextos ameríndios se entregam a uma miríade de rituais, se iniciando, muitas vezes, em suas práticas. A tese de Lima (1995), posteriormente publicada em livro (2005) é permeada por reflexões sobre a sua posição na trama, a servir e ser servida pelos homens durante as cauinagens yudjá. A autora-etnógrafa observa, com sensibilidade, sua própria presença na aldeia. As tensões sobre sua autonomia, as respostas yudjá aos seus "caprichos de bêbada", são matéria viva da análise. Mais recentemente, Joana Cabral de Oliveira (2012) ancora sua reflexão em inúmeras idas a roça, pescarias, coletas, expedições de caça e deslocamentos entre as aldeias wajãpi, numa etnografia realizada em movimento, que versa, justamente, acerca dos deslizamentos constantes entre os domínios conceituais dessas pessoas indígenas. No mesmo sentido, em sua etnografia, Fabiano Bechelany (2017) narra as tantas expedições de caça que realizou junto aos Panará, observando desde essa perspectiva interna o fluxo das transformações e os desafios enfrentados por essas pessoas na atualidade. 
Podemos também aludir ao estudo sobre os mitos, cestaria e canções yekuana (grupo karib da Venezuela) realizado por David Guss (1989). Depois de abandonar a procura do grande mito de origem yekuana (que ele sabia existir em textos antigos), o autor decide, desiludido, sentar-se com as pessoas mais velhas e aprender a arte de trançar cestos. O que ele descobre, por esse modo, é que a vida yekuana é como o trançado, ou, em outras palavras, que o trançar era a metáfora-chave para a vida desse povo, e que fragmentos e partes do mito de origem eram trançados, proferidos e cantados pelas pessoas mais velhas todos os dias, no crepúsculo, quando sentavam juntas num círculo. O resultado da iniciação de Guss nas técnicas de trançado yekuana foi um profundo entendimento da ontologia yekuana (apud LAGROU 2007: p. 50).

Os exemplos se amontoam; outras tantas antropólogas e antropólogos acompanham em suas pesquisas as atividades das pessoas com quem estudam, engajando-se nelas. Como dita o cânone antropológico, observam e participam das vidas de suas interlocutoras e interlocutores. Roçam com elas, preparam com elas os alimentos, participam com elas de certos rituais. Deixam que lhes cortem os cabelos, que lhes pintem os corpos, algumas vezes até que lhes perfurem os lábios, o nariz, as orelhas. Ainda assim, a dimensão de modulação do corpo, isto é, a dimensão afetiva dessas experiências, para lembrar Deleuze e Guattari (1992), é convencionalmente pouco explorada.

Antropólogas e antropólogos que pesquisam os mais variados temas estabelecem analogias entre a dimensão formal de suas experiências em campo e a dimensão formal, lógica, que seria subjacente aos mundos dos outros que protagonizam suas etnografias. Observam nos outros os efeitos de sua participação, como o fez Guss quando, aprendendo a trançar, descobriu que os mitos de origem yekuana eram eles mesmos o ato yekuana de trançar os cestos. A forma como o movimento da produção da cestaria pelo etnógrafo acresce ao aprendizado sensível dos mitos, entretanto, nos escapa. Afinal, convencionalmente não é permitido ao corpo do autor-etnógrafo testemunhar, legitimamente, a existência de um mundo aquém ou além-palavra.

Mas a convenção, sabemos, sempre encontra seus dissidentes. Antropólogas e antropólogos como Jeanne Favret-Saada (1977), Carlos Castañeda (1971), Loïc Wacquant (2002), cada um à sua maneira, destoam da prescrição intelectualista do fazer antropológico. Passaram por experiências de transformação corporal que infletiram seus caminhos em campo, modificaram seu modo de se portar ali, modificaram as perguntas que faziam a suas interlocutoras e interlocutores, modificaram o que pretendiam em suas pesquisas. No limite, modificaram suas vidas.

A crença na universalidade fundamental e primeva da lógica racionalista tem levado antropólogas e antropólogos a fazer as mesmas perguntas, a tentar as mesmas soluções formais e inventariar as respostas de suas interlocutoras e interlocutores. De que modo determinados sujeitos entendem a si mesmos? De que modo entendem os outros? Questões como essas pressupõem o intelecto como eixo central de toda ontologia e se repetem nos projetos de pesquisa. Aos poucos, a ênfase intelectualista se afunda na estagnação decorrente 
da repetição exaustiva das mesmas formulações. Para avançar é preciso fazer novas perguntas, é preciso abrir-se a novos modos de conhecer.

\section{Levanta-te e dança!}

Decidido a investigar práticas corporais e processos de criação de danças contemporâneas fundadas na improvisação, Renato Jacques foi instigado por sua orientadora, Rose Satiko, que já praticava tais danças, a, para além de observar, dançar. Até então, a experiência de campo havia se dado em modo sentado, quadris devidamente imobilizados, olhar fixo e apartado, caderno e lápis em riste. Dizer sim a tal provocação foi o começo de um novo modo, ou melhor, de um novo mundo de conhecer, relacionar, ser.

Os principais ancoradouros desse percurso etnográfico foram as companhias paulistanas Núcleo Artérias, dirigida por Adriana Grechi; key zetta e cia, dirigida por Key Sawao e Ricardo Iazzetta; e Sansacroma, dirigida por Gal Martins ${ }^{3}$. O primeiro material etnográfico daí advindo é a resistência oferecida por um corpo que, por vinte e oito anos, fora longa e arduamente treinado ao hábito de pensar sentado em cadeiras. A primeira lição etnográfica daí advinda é que quem pensa agora é o corpo, em movimento. Seu movimento é o que você está pensando. Improvisar em dança, o corpo em que se pode estar, recoloca o pensamento em condição de risco, por exemplo, de cair, de se chocar, se machucar. E isso constitui a dança enquanto conhecimento. $\mathrm{O}$ risco adquire efeitos epistemológicos. E nesse sentido, dançar não é o que parece ser quando olhamos alguém a dançar com os olhos distantes do intelectualismo linguístico.

O experimento de Renato nos convoca a assumir a possibilidade de produzir conhecimento não apenas através da visão associada ao intelecto parado. Sua etnografia em meio às práticas corporais de grupos de danças contemporâneas levou sua pesquisa a realidades que passariam ao largo de um corpo sedado, assistente e escrivão. Na distância do olhar constituído enquanto tal, elementos fundamentais a essas danças ficam de fora, por exemplo, o sentido do peso, ou melhor, o peso enquanto sentido. $O$ corpo longa e arduamente assentado perde o controle e a noção do peso, se desapropria do peso de seus pés, de suas pernas. O corpo que conhece sentado aliena, quiçá, o próprio peso do conhecimento, achatando-o sobre uma superfície plana e suspensa. Por sua vez, o corpo que dança assume, de saída, uma outra perspectiva ontológica: pesa, logo existe.

Enquanto um corpo passa horas sentado a ler palavras numa superfície, outro passa horas a estudar o peso de cada movimento. O peso dos braços, o peso dos pulmões, o peso do pensamento. As danças contemporâneas conquistam, diariamente, toda uma outra perspectiva em relação ao chão e ao peso. Nessas danças, do chão não nos afastamos jamais. Pelo contrário, vamos em direção a ele, rolando, rastejando, roçando-nos nele, precisamos inteiramente dele, corpos entregues a ele, a tudo o que o chão pode fazer por nós. Essas

\footnotetext{
3 Para mais, ver "Ensaio ao pé da letra: Etnografando processos criativos de danças contemporâneas" (JACQUES 2015) e "Ensaiando corpos: A dança contemporânea, o improviso e a indomesticação (co)movente do pensamento" (JACQUES 2019).
} 
danças ensinam que é preciso aprender a lidar com o chão, a corresponder com ele, o que para um corpo sentado-suspenso é literalmente aprender outra língua. Só que essa língua é outro corpo, outro mundo. Um mundo no qual o movimento é modo de ser e não mera reação mecânica aos comandos da "mente". Um mundo no qual podemos nos mover pelo pensamento dos pés, dos quadris, da coluna etc. Qualquer segmento designado do corpo pode se fazer ser, se fazer sentir, se emancipar enquanto centro motriz e reverberador de movimento. Os pulmões, por exemplo, podem ganhar a força de divindades pelas quais somos tomados. Há danças inteiras fundadas na experimentação respiratória, que têm os pulmões, reais e imaginados, por centro nervoso, nas quais a respiração é acionada como motriz de variações rítmicas e qualidades corporais. A respiração conduzindo o movimento que nos conduz. Inspira. Expira.

Algumas técnicas de improvisação que permeiam as danças contemporâneas podem alterar gestos aparentemente "naturais" e que não seriam tomados por "dança", sentar-se, estar de pé, caminhar, respirar, olhar, ouvir. Descolonizar o sentido do caminhar, abrindo temporalidades no espaço de cada passo, disponibilizando de novas maneiras o corpo a partir de novas atenções. Estudar o caminhar atentando para o jogo de forças no qual se dá, levando a sério a sensibilidade dos pés, conhecendo um fazer em tudo tátil, no qual os pés se tornam mãos de caminhar, pés que pegam o chão.

Para uma tal descolonização dos pés, vasta é a gama das atenções dadas a eles nas práticas que permeiam as danças contemporâneas. Os pés ganham toques, manipulações, imaginações, olhares. Pode ser que tais experiências tenham início no simples enunciado "agora vamos olhar com os pés", e de tanto experimentar isso, o imaginado se faz sensível e, uma vez os olhos nos pés, faz-se o mundo da perspectiva pisante, pautada num pisarconhecer. Seu alongamento é intensificado, seu contorno é aceso, abre-se mesmo lugares nos pés, que acolhem novos movimentos, permitindo ao corpo novas propensões, pessoais e interpessoais, desde os pés. O que toca primeiro o chão, como se distribui o peso, e como isso se relaciona com meus quadris e o modo como eu olho, toco, relaciono-me.

E se a dança muda o corpo que dança, com o passar do tempo, ela altera a qualidade com que esse corpo vê dança. Olhar se torna parte do que se vê. Um olhar mais inclusivo do que exclusivo. Um olhar como qualquer coisa menos vetor de distanciamento e/ou objetificação.

Muda-se o sentido dos pés, pernas, joelhos, quadris, muda-se a pessoa que descobre que mal sentia os (não tão) próprios pés, pernas, joelhos, quadris, descobrindo que "tê-los" não é garantia de senti-los. Trata-se de uma conquista de realidade, de presença, uma reintegração corporal. As danças contemporâneas recolocam, assim, o corpo como território político, existencial, relacional. E aqui não estamos representando, não estamos meramente fazendo metáforas, a não ser que possamos estender o conceito de metáfora e chamar tais danças de experiências metafóricas, numa semiótica viva, na qual pessoas têm sua forma literal estendida a novas relações de sentido (Wagner, 1972). Nesse caso, a pessoa que dança 
é poderosa porque transcende as limitações significantes da própria (noção de) pessoa, encorporando a transformação.

\section{Uma volta em Canarana}

Localizada no centro-leste do Mato Grosso, Canarana é um dos dez municípios que compõem a área do Território Indígena do Xingu (TIX). Sediando as principais instituições de atendimento social, a FUNAI regional e diversas organizações indígenas, Canarana abriga uma grande quantidade de pessoas indígenas vindas das diferentes regiões do TIX. Por essa razão, ainda em 2013, Amanda Horta escolheu realizar ali o trabalho de campo que deu origem à sua tese de doutorado (HORTA 2018). Canarana é uma cidade repleta de indígenas de etnias e línguas distintas, gente vinda do TIX que vai, vem e, às vezes, firma residência por lá.

A cidade não é apenas um espaço inerte aguardando a ressignificação indígena, mas produz corpos e diferencia as diferenças entre as pessoas que se relacionam ali, infletindo as maneiras indígenas de estar no mundo. As pessoas indígenas do TIX não pretendem se portar na cidade da mesma maneira como se portam na aldeia - isso seria estupidez - e elas não se portam, sendo essas outras formas de existir o principal objeto da referida tese. Os brancos não são como os índios, os diferentes indígenas não são todos parentes entre si e a cidade não é uma aldeia. Indígenas vindos do TIX sabem disso.

Em 2017, em Canarana, Amanda conversava com Kahala ${ }^{4}$, uma mulher altoxinguana que contava ter se mudado para essa cidade dez anos antes, quando ainda "não tinha índio" ali. Naquela época, dizia ela, era muito melhor. "[Hoje,] Canarana é uma cidade com índios demais. O pessoal fala muito”.

Eu nem ando com índio aqui não, só Sarah que é minha amiga. E mesmo assim, ela não vai na minha casa e eu não vou na casa dela. Aqui não é igual aldeia, que você chega e tem aquele tanto de gente na casa. Aqui é de branco. Eu penso igual branco (KAHALA, janeiro de 2017).

Parte importante da resposta de Kahala é justo esse contraste: desde a perspectiva citadina, as pessoas indígenas enfatizam a descontinuidade entre as experiências da cidade e da aldeia, e apoiam nessa oposição muitas de suas formulações sobre sua experiência no espaço urbano. Assim, para Kahala, viver a experiência da cidade de forma produtiva implicava recusar estabelecer ali o modo de relação característico das aldeias - recusar ter a casa cheia de parentes, recusar o ato de produzir o que se consome, recusar dormir as noites em redes. Esta seria uma das formas através das quais as pessoas indígenas do TIX moldam seus corpos, tornando-os mais aptos à vida em Canarana e às relações com as pessoas não indígenas em geral. Afinal, Canarana é terra de não indígenas e são os modos dessa gente

\footnotetext{
${ }^{4}$ Em ordem de preservar a privacidade da interlocutora, o nome é fictício.
} 
que ditam o modo convencional de ali se viver. Cada lugar traz consigo um modo de existir e a adequação entre o espaço e o modo de vida que ele determina é também índice de segurança: agir assim diminui as chances de Kahala ser enganada pelos brancos, diminui as chances de outras pessoas indígenas fazerem fofocas sobre ela (e, como ela disse, "o pessoal fala muito"), diminui as chances de outras pessoas, independentemente de sua identidade étnica, lhe fazerem mal (HORTA 2018).

A presença em Canarana, porém, não se desenha apenas pela negação da vida na aldeia, havendo também uma dimensão positiva da formulação que as pessoas indígenas do TIX fazem de suas experiências na cidade. Como vimos, os ameríndios modulam diferenças sociológicas através de transformações corporais e esse procedimento de produção de pessoas é fundamental também para os indígenas do TIX. Estar na cidade, portanto, requer modulações corporais bastante específicas. O jeito próprio à cidade de se dormir é numa cama, modo como ali dormem os não indígenas, preferencialmente distantes dos muitos parentes que costumam dormir juntos na aldeia. Além disso, na cidade se está sempre sentado. Um amigo Kuikuro disse, certa vez, que na cidade, tudo que se fazia era seguido de um descanso: faz-se qualquer coisa e se "senta um pouquinho". Ele dizia isso rindo, como que fazendo troça com os brancos. Ainda assim, estavam, ele e Amanda, sentados no quarto de hotel onde ele ficava, um espaço de cerca de cinco metros quadrados onde ele se apertava entre a cama e o ventilador, mas ficava "sentado como um branco".

Nas cidades ou nas aldeias, mulheres e homens indígenas do TIX se engajam cada vez mais no projeto de conhecer o conhecimento dos outros 5 . Dormir na cama, defecar na privada, falar português, sentar-se nas carteiras escolares por horas a fio: mesmo que desconfortáveis, difíceis, maçantes, dolorosos até, são atos que moldam o corpo e muitas pessoas indígenas estão dispostas a enfrentá-los para se acostumar a viver como os brancos e conseguir, assim, travar relações mais simétricas com eles. A forma como as pessoas indígenas do TIX usam o termo "acostumar" é interessante, pois se coloca em continuidade com o termo "costume", no sentido mesmo de "uma maneira de se comportar própria a uma pessoa ou sociedade" (DICIO 2020). Ter um costume, portanto, seria "estar acostumado a" um determinado conjunto de afetos (HORTA 2017). Acostumar-se às ações citadas acima, referentes à vida na cidade, torna as pessoas indígenas, segundo elas mesmas afirmam, mais aptas a negociar com os brancos, a lutar as lutas de papel $^{6}$, a não ser enganadas pelas suas palavras de amizade, a manter sua autonomia nesse mundo outro que é Canarana. Mas, no caso que abre esta seção, para dizer da forma como vive em Canarana, Kahala não fala

\footnotetext{
${ }^{5}$ Em artigo sobre os efeitos que as imagens de conhecimento projetadas pelas políticas culturais têm sobre os regimes de criatividade nativos, Coelho de Souza (2004) discute o fato de que os Kĩsêdjê, povo de língua Jê que habita uma das quatro terras indígenas contíguas que compõem o Território Indígena do Xingu, "se encontram tão engajados no projeto de conhecer o conhecimento dos outros (...) quanto em ver seu conhecimento conhecido por outros".

${ }^{6}$ Muitos indígenas do TIX (e também de outras etnias no Brasil), afirmam que as guerras que hoje travam com os brancos são guerras que não se lutam corpo-a-corpo, mas através de documentos e palavras escritas.
} 
daquilo que ela faz, dos seus modos de comer, de agir, de dormir. Ao contrário, ela diz que, na cidade, ela pensa igual branco. A opção pela palavra pensar é, aqui, extremamente perspicaz: se o que define a existência na aldeia são modos do corpo (seu modo de estar, de comer, de festar, de dormir), o que definiria, segundo Kahala, a existência na cidade, seria um modo de pensar.

\section{Atando nós}

O relato de Kahala demonstra que aquilo que ela entende sobre os brancos é mais do que uma projeção daquilo que ela conhece de seu próprio mundo. Não há solipsismo aqui, o que há é a mais franca comunicação. As pessoas indígenas do TIX continuam aplicando com sucesso seus corpos a fim de conhecer outras realidades e, mesmo que tudo indique que a dimensão corporal importa, a experiência já parece ter mostrado a elas - essas grandes interlocutoras de mundos - que, desde a perspectiva dos brancos, a dimensão intelectual é fundamental. À medida em que conhecem melhor os brancos, mulheres e homens indígenas do TIX não parecem requerer equivalência entre a forma como vivem a própria existência e a forma como vivem a existência dos não indígenas: as diferenças são diferentes - e isso parece bastar.

O que está em questão não é se Kahala logra experimentar a vida dos brancos, nem mesmo se Renato é capaz de reproduzir em seu corpo as experiências das dançarinas e dançarinos com quem realiza sua etnografia. O que está em questão é o fato de que ambos são capazes de habitar existências outras às da mente, e de experimentar o corpo como instância de modulação do conhecimento. O que ressalta, dentre outras coisas, o cair, se machucar, ficar roxo, mas também o caminhar, o correr, o rebolar enquanto conhecimento. Com isso, os movimentos da existência se tornam uma urgência de cujas consequências não se pode escapar. O corpo que erra, que entra em movimento para conhecer, agora corre, e corre perigo. Perigo de vida, perigo de conhecer. Quando levamos a sério os riscos que a floresta apresenta às pessoas indígenas, colocamos nossos corpos à espreita dos espíritos, fazendo disso uma ameaça, se não ao nosso corpo, sem dúvida aos corpos de nossas amigas e amigos interlocutores com quem nos movemos nessas situações. O medo presente nessas experiências dota nossos textos de uma dimensão de risco iminente fundamental para a expressão antropológica dessas realidades. Os afetos, finalmente, afetam, e não apenas aqueles com uma determinada "visão de mundo". A dor do outro deixa de ser uma mera questão social alheia e pode finalmente tocar, mobilizar, fazer agir.

Em um texto recente, Marcela Coelho de Souza (2017) sugere que os regimes de alteração ameríndios - as transformações xamânicas, os processos de virar-outro, de virarbranco - devem levar em conta o perigo que os ameríndios afirmam estar implicado nesses processos. Seria fundamental, aqui, levar a sério o que está em jogo, segundo as próprias pessoas indígenas: “(a) saber, o risco de morte”. A morte para essas pessoas, a autora continua, não é um processo irreversível e isso não deve nos levar a diminuir a ansiedade envolvida nesse acontecimento. É preciso que essa morte seja tomada não como um 
malabarismo mental indígena, mas como o processo corporal que as pessoas indígenas o afirmam ser. Se o perigo de cair muda o entendimento daquilo que se conhece através da dança, também o perigo de morrer transforma os modos de habitar mundos. Reduzir regimes de alteração à sua dimensão intelectual, estrutural, lógica, eclipsando suas consequências corporais - o corpo como veículo de conhecimento - implica recusar e deslegitimar a possibilidade mesma de existência de mundos diferentes, resistentes, contrahegemônicos.

Nesse mesmo sentido, as Cosmopolíticas de Isabelle Stengers (2011) nos ajudam a refinar esta proposição, através da referência à etnopsiquiatria de Tobie Nathan. Segundo a autora, para Tobie Nathan a atuação de uma etnoterapeuta - que em muitos sentidos se assemelha às experiências antropológicas - não requer que ela perceba as agências nãohumanas da mesma forma como aqueles com quem realiza sua prática terapêutica afirmam percebê-las. Na mesma medida, a questão não é perceber o mundo como nossas interlocutoras e interlocutores de pesquisa percebem. Não se trata de uma obrigação de "pertencer" a um determinado grupo, de se identificar com ele, para então acessar seus modos e entendimentos de vida. Antes, trata-se da obrigação de reconhecer, de uma maneira que não seja apenas uma reflexão, o próprio pertencimento dessas pessoas (STENGERS 2011: p. 334-5). Conhecer e reconhecer, através do corpo, mundos que não são concebidos em modo sentado permite um engajamento com essa dimensão urgente e resistente de suas existências. Mas, para dizer "o corpo", é preciso perguntar qual corpo, feito por quem e como. O que o agita e como, o que o toca e como, o que o sacode e como, o que o machuca e como, o que o põe em risco, em risco de que, e como. O que um corpo faz? Grita? Chora? Pula? Agacha? E mais do que um compêndio de diferentes modos corporais, talvez precisemos passar a especular os efeitos ontológicos, cosmológicos até, do engajamento existencial desse ou daquele corpo no mundo em que habita. Para dizer de uma corporeidade é preciso atentar para atos, gestos que fazem corpos, corpos que fazem outros corpos, oscilando entre qualidades corporais e modos de existir. No que implica tal ou qual qualidade ou modo? Que mundos se abrem a essa ou àquela modulação? O que acontece sob uma simples alteração entre o lento e o rápido, entre o sentar e o caminhar, entre o escrever e o falar, entre o ser e o estar?

O próprio verbo ser, do espanhol e do português, é formado a partir do latim sedere, ou seja, sentar (LAPLANTINE 2015). Sendo os termos sedere e sedare etimologicamente irmanados, a própria questão do ser se revela uma questão sedada e, desde tal perspectiva, responder "quem é" determinado grupo de pessoas, recai, outra vez, sobre um certo intelectualismo, que reduz o outro ao que esse "entende" de si. Postula-se o ser desde a estabilidade de uma existência dada sob um tipo específico de sentar, aliado a cadeiras, mesas, canetas, lápis, folhas, telas. Mas, como sabemos, há vários outros modos de existir e, na mesma medida, vários outros modos de sentar.

Cabe lembrar que a figura do "homem sentado" tem relevância no pensamento ameríndio em geral (PINEDA CAMACHO, 1996; URBINA, 1994 apud GUERREIRO, 
2012). Contudo, longe de sedar, sentar ao modo ameríndio requer uma "postura corporal impressionante, muito diferente da nossa nas cidades, que mal nos permite ficar de cócoras ou sentados com as pernas esticadas e as costas retas por poucos minutos sem sentir dor" (BELAUNDE 2016: p.49). A postura ameríndia modela o corpo, que, nestes contextos, é produzido em diferença àqueles que ficam de pé.

Talvez Kahala nos esteja chamando a atenção para o estar e para a dissimetria entre o ser branco e o estar branco, desde sua perspectiva indígena. Talvez, entre a existência sincrônica daquilo que somos e as maneiras como estamos, como instituímos nossas presenças, não exista a hierarquia que aponta o ser como cerne, como mote primeiro, como raiz. Talvez, tanto para o corpo de Renato e das dançarinas e dançarinos com quem, em alguns momentos, compartilha o espaço, o chão e o movimento, quanto para o corpo de Kahala, que cresceu numa aldeia do alto Xingu e vive agora, a maior parte de seu tempo, em uma casa de alvenaria cercada de asfalto, o ser que pensa sentado sobre uma cadeira, seja apenas um estado possível dentro de uma miríade de formas de estar.

\section{Referências Bibliográficas}

BAITELLO, Norval. (2012). O pensamento sentado. Sobre glúteos, cadeiras e imagens. São Leopoldo, RS: Editora da Universidade do Vale do Rio dos Sinos.

BELAUNDE, Luisa Elvira. (2016). Corpo terra - Tempo lua: Reflexões sobre o chão e a incerteza entre os Quechua-lamas da Alta Amazônia Peruana. In: Incerteza Viva. São Paulo: Fundação Bienal de São Paulo.

BECHELANY, Fabiano Campelo. (2017). Suasêri: a caça e suas transformações com os Panará. Tese de Doutorado em Antropologia. Brasília: Brasília: PPGAS-UNB.

CASTAÑEDA, Carlos. (1971). Uma estranha realidade. Rio de Janeiro: Editora Record.

CORREA XAKRIABÁ, Célia Nunes. (2018). O Barro, o genipapo e o giz no fazer epistemológico de autoria Xakriabá: reativação da memória por uma educação territorializada. Dissertação de Mestrado em Sustentabilidade junto a Povos e Terras Tradicionais. Brasília: PPG-Sustentabilidade, UNB.

COELHO DE SOUZA, Marcela Stockler. (2014). Conhecimento indígena e seus conhecedores: uma ciência duas vezes concreta. In: CARNEIRO DA CUNHA, Manuela; CESARINO, Pedro. (Orgs.). Políticas culturais e povos indígenas. São Paulo: Cultura Acadêmica.

COELHO DE SOUZA, Marcela Stockler. (2017). Uma irritante duplicidade: breve nota sobre a contramestiçagem e os Kisêdjê. In: R@U - Revista de Antropologia da UFSCar, vol.9, n.2.

DELEUZE, Gilles e GUATTARI, Felix. (1992). O que é a Filosofia? Tradução de Bento Prado Jr. e Alberto Alonso Muñoz. São Paulo: Editora 34.

DICIO. (2020). Dicionário Online de Português. Disponível em: https://www.dicio.com.br/costume/ Último acesso em junho de 2020. 
FAVRET-SAADA, Jeanne. (1977). Les mots, la mort, les sorts. Paris: Gallimard.

GOLDMAN, Marcio. (2016). Mais alguma antropologia: ensaios de geografia do pensamento antropológico. São Paulo: Ponteio.

GUSS, David. (1989). To Weave and Sing: Art, Symbol and Narrative in the South American RainForest. Berkeley: University of California Press.

GUERREIRO, Antônio. (2012). Ancestrais e suas sombras: Uma etnografia da chefia kalapalo e seu ritual mortuário. Tese de Doutorado em Antropologia Social. Brasília: PPGASUnB.

HORTA, Amanda. (2018). Relações indígenas em Canarana. Tese de doutorado em Antropologia Social. Rio de Janeiro: PPGAS Museu Nacional-UFRJ.

HORTA, Amanda. (2017). Indígenas em Canarana: notas citadinas sobre a criatividade Parque-Xinguana. In: Revista de Antropologia, n.60, v. 1.

INGOLD, Tim. 2008. Pare, olhe, escute! Visão, audição e movimento humano. In: Ponto Urbe, n.3.

JACQUES, Renato. (2015). Dançando estruturas: Lévi-Strauss, Alfred Gell e a dança contemporânea. In: Cadernos de Campo, n.24, v.24.

JACQUES, Renato. (2015). Ensaio ao pé da letra: etnografando processos criativos de danças contemporâneas. São Paulo: Editora Biblioteca 24 Horas.

JACQUES, Renato. (2019). Ensaiando corpos: a dança contemporânea, o improviso e a indomesticação (co)movente do pensamento. In: Revista Tessituras, n.2, v.7.

LAGROU, Els. (2007). A fluidez da forma: arte, alteridade e agência em uma sociedade amazônica (Kaxinawa, Acre). Rio de Janeiro: TopBooks.

LAPLANTINE, François. (2015). The life of the senses: Introduction to a modal anthropology. New York: Bloomsbury.

LATOUR, Bruno. (2000). Ciência em ação: como seguir cientistas e engenheiros sociedade afora. São Paulo: UNESP.

LATOUR, Bruno. (2004). Politicas da natureza: Como fazer ciência na democracia. Tradução de Carlos Aurélio Mota de Souza. Bauru: Edusc.

LÉVI-STRAUSS, Claude. (1989). O Pensamento selvagem. Campinas: Papyrus.

LIGIÉRO, Zeca. (2011). O conceito de “motrizes culturais” aplicado às práticas performativas afro-brasileiras. Revista Pós Ciências Sociais, vol.8, n.16.

LIMA, Tânia Stolze. (1995). A parte do Cauim: Etnografia juruna. Tese de Doutorado em Antropologia Social. Rio de Janeiro: PPGAS Museu Nacional - UFRJ.

LIMA, Tânia Stolze. (2002). O que é um corpo? In: Religião e Sociedade, Rio de Janeiro, vol.22, n. 1.

LIMA, Tânia Stolze. (2005). Um Peixe olhou para mim: O povo Yudja e a perspectiva. São Paulo: UNESP/ ISA/ NUTI.

MERLEAU-PONTY, Maurice. (1968). The Visible and the Invisible, followed by working notes. Evanston, Northwestern: University Press. 
OLIVEIRA, Joana Cabral de. (2012). Entre plantas e palavras: Modos de constituição de saberes entre os Wajãpi. Tese de Doutorado em Antropologia Social. São Paulo: PPGAS USP.

SEEGER, Anthony; DA MATTA, Roberto; VIVEIROS DE CASTRO, Eduardo. (1979). A construção da pessoa nas sociedades indígenas brasileiras. In: Boletim do Museu Nacional, vol.32.

STRATHERN, Marilyn. (2006). O Gênero da dádiva: problemas com as mulheres e problemas com a sociedade na Melanésia. Tradução de André Villalobos. Campinas: Editora da Unicamp.

STENGERS, Isabelle. (2011). Cosmopolitics II. Translated by Robert Bononno. Minneapolis: University of Minnesota Press.

STENGERS, Isabelle. (2017). Reativar o animismo. Tradução de Jamille Pinheiro. Belo Horizonte: Chão de Feira;

TAYLOR, Anne-Christine. (1996). The Soul's body and its states: An Amazonian perspective of being human. In: The Journal Of The Royal Anthropological Institute. Vol. 2, No. 2.

VILAÇA, Aparecida. (2005). Chronically unstable bodies: Reflexions on Amazonian corporalities. In: The Journal of the Royal Anthropological Institute, vol.11, n.3.

VIVEIROS DE CASTRO, Eduardo. (2002). A Inconstância da alma selvagem e outros ensaios de antropologia. São Paulo: Cosac \& Naify.

VIVEIROS DE CASTRO, Eduardo. (2012). “Transformação” na antropologia, transformação da "antropologia”. In: Mana vol.18, n.1.

WACQUANT, Loïc. (2002). Corpo e alma: notas etnográficas de um aprendiz de boxe. Rio de Janeiro: Relume-Dumará.

WAGNER, Roy. (1972). Habu: The innovation of meaning in Daribi Religion. Chicago: The University of Chicago Press.

WOLPERT, Daniel. (2011). A razão para os cérebros existirem. (17m59s). TED. Disponível em: https://www.youtube.com/watch?v=7s0CpRfyYp8\&t=427s Último acesso $7 / 11 / 2021$.

\begin{abstract}
Amanda Horta
Doutora e mestre em Antropologia Social pelo Museu Nacional da Universidade Federal do Rio de Janeiro, e graduada em Ciências Sociais pela Universidade Federal de Minas Gerais.
\end{abstract}


HORTA; JACQUES | Pesa, logo existe: por uma antropologia que corra (perigo) | 18

\section{Renato Jacques}

Doutorando e mestre em Antropologia Social pela Universidade de São Paulo, graduado em Ciências Sociais pela Universidade Federal de Minas Gerais.

Recebido em 22/06/2020

Aceito para publicação em 27/12/2020 